\title{
Faktor-Faktor yang Memengaruhi Kinerja Usaha Kerajinan Rotan di Kabupaten Cirebon
}

\author{
Donny Perkasa, Sarwo Edy Handoyo \\ Program Studi Manajemen Fakultas Ekonomi \& Bisnis \\ Universitas Tarumanagara \\ Email : donnyperkasa5@gmail.com
}

\begin{abstract}
The purpose of this study was to determine and analyze the effect of risk taking, proactivity, autonomy and competitive aggressiveness on the performance of rattan handicraft businesses in Cirebon Regency. The method of determining the sample using non-probability sampling method with the type of purposive sampling. Data collection methods using a questionnaire distributed to 100 respondents. Data analysis uses SEM PLS analysis. The results of the analysis concluded that there is an influence of risk taking, proactivity, autonomy and competitive aggressiveness on the performance of the rattan handicraft business in Cirebon Regency.
\end{abstract}

Keywords: Innovation, Risk Taking, Proactive, otonomy, competitive aggressiveness

Abstrak: Tujuan penelitian ini adalah untuk mengetahui pengaruh pengambilan risiko, proaktif, otonomi dan agresivitas bersaing terhadap kinerja usaha kerajinan rotan di Kabupaten Cirebon. Metode penentuan sampel menggunakan metode non probability sampling dengan jenis purposive sampling. Metode pengumpulan data dengan menggunakan kuesioner yang di bagikan kepada 100 responden. Analsisi data menggunakan analisis SEM PLS. Hasil analisis menyimpulkan bahwa terdapat pengaruh pengambilan risiko, proaktif, otonomi dan agresivitas bersaing terhadap kinerja usaha kerajinan rotan di Kabupaten Cirebon.

Kata Kunci: inovasi, pengambilan risiko, proaktif, otonomi, aggresivitas bersaing

\section{LATAR BELAKANG}

Kewirausahaan berperan penting di dalam perkembangan perekonomian suatu negara. Banyak ahli menyebutkan bahwa kewirausahaan telah memberi kontribusi yang signifikan terhadap pertumbuhan dan perkembangan sosio-ekonomi suatu negara, seperti kesempatan kerja dan pertumbuhan ekonomi yang pada gilirannya akan meningkatkan kesejahteraan nasional. Terlebih pada situasi krisis yang berkepanjangan, peran wirausahawan dirasakan sangat penting (Tambunan, 2009).

Salah satu usaha yang memiliki potensi yang cukup besar untuk dikembangkan yang ada di Jawa Barat khususnya di Kabupaten Cirebon adalah usaha kerajinan rotan. Usaha kerajinan rotan merupakan salah satu tumpuan utama Pemerintah di Kabupaten Cirebon dalam menciptakan lapangan kerja baru terutama setelah krisis ekonomi yang terjadi beberapa tahun yang lalu. Produk industri kerajinan rotan sendiri mempunyai nilai ekonomis yang tinggi, sehingga menjadi komoditas unggulan ekspor di Kabupaten Cirebon. Adapun jenis produk yang dihasilkan berupa perabotan rumah tangga seperti meja, kursi, rak, keranjang, dan produk kerajinan lainnya.

Industri kerajinan rotan memberikan kontribusi terbesar terhadap perekonomian di Kabupaten Cirebon dibandingkan dengan industri lainnya. Dengan kapasitas dan nilai produksinya yang besar, sentra industri rotan merupakan industri padat karya dan sebagian besar produknya untuktujuan ekspor sehingga mampu memberikan lapangan pekerjaan bagi masyarakat Kabupaten Cirebon. Menurut Dinas 
Perindustrian dan Perdagangan Kabupaten Cirebon, pelaku industri kerajinan rotan tidak hanya industri besar saja, namun juga didominasi oleh industri kecil dan menengah. Industri kerajinan rotan di Kabupaten Cirebon sebagai sentra industri rotan terbesar di Indonesia, namun dalam perkembangannya tidak selalu berjalan dengan baik, diantaranya adalah perkembangan nilai ekspornya yang mengalami fluktuatif setiap tahunnya. Dalam perkembangannya, persaingan industri kerajinan rotan ini tidak hanya dalam tingkat makro saja, namun bisa juga dilihat di tingkat mikro yang dimiliki oleh perusahaan secara personal maupun kelompok. Selain itu, persaingan juga datang dari industri yang sama yang berada di luar wilayah Cirebon. Dalam berwirausaha, seorang pengusaha harus memiliki inovasi-inovasi baru dalam menciptakan produk, serta memiliki perilaku proaktif dalam menjalan usaha, serta berani mengambil risiko dalam usahanya karena semakin besar risiko yang dihadapi maka akan semakin besar pula keuntungan yang akan didapat. Selain itu seorang pengusaha harus memiliki autonomi dalam diri mereka, mereka tidak bisa di intervensi oleh orang lain dalam mengelola usaha dan memiliki sikap agresivitas kompetitif terhadap pesaing-pesaing mereka agar kinerja usahanya semakin meningkat. Oleh karena itu, penelitian ini diberi judul "Pengaruh Inovasi, Pengambilan Risiko, Proaktif, Otonomi dan Agresivitas Bersaing terhadap Kinerja Usaha Kerajinan Rotan di Kabupaten Cirebon".

\section{KAJIAN TEORI}

Knight (2000) menjelaskan bahwa orientasi kewirausahaan berkaitan dengan pencarian pelaung, keberanian pengambilan resiko dan keputusan untuk bertindak dari para pemimpin organisasi atau perusahaan. Sehingga orientasi kewirausahaan menjadi penggerek dan penentu strategi suatu perusahaan. Zimmerer dan Scarborugh (2008) menyatakan bahwa sukses kewirausahaan akan tercapai apabila berfikir dan melakukan sesuatu yang baru atau sesuatu yang lama dengan cara baru.orientasi kewirausahaan dan perilaku kewirausahaan yang proaktivennes meningkatkan kinerja pemasaran untuk perusahaan yang beroperasi dalam lingkungan yang dinamis. Orientasi terbagi dalam lima dimensi (Lee dan Peterson, 2000), yaitu:

Keinovasian (innovativeness). Keinovatifan adalah kecenderungan untuk terlibat dalam kreatifitas dan eksperimen melalui pengenalan produk atau jasa baru serta kepemimpinan teknologi melalui riset dan pengembangan dalam proses-proses baru.

Pengambilan resiko (risk tasking). Pengambilan resiko adalah pengambilan tindak tegas dengan mengekplorasi halyang tidak diketahui, meminjam dalam jumlah besar dan atau mengalokasikan sumber daya yang signifikan untuk usaha dilingkungan yang tidak pasti.

Proaktif (pro-activeness). Proaktif adalah sebuah pencarian peluang, perspektif memandang ke depan yang ditandai dengan pengenalan produk baru atau jasa baru lebih dulu dalam persaingan dan bertindak dalam mengantisipasi permintaan masa mendatang.

Keagresifan bersaing (competitive agressiveness). Keagresifan bersaing adalah intensitas dari upayaupaya perusahaan untuk mengungguli pesaing dan ditandai oleh sikap atau tanggapan ofensif atau respon agresif terhadap tindakan- tindakan pesaing.

Otonomi (autonomy). Otonom merupakan untuk bekerja secara mandiri, membuat keputusan dan mengambil tindakan yang bertujuan untuk memajukan konsep bisnis dan membawanya pada penyelesaian.

Kerangka pemikiran di dalam penelitian ini adalah kinberja usaha sebagai variabel Y dan dipengaruhi oleh Innovasi, Pengambilan Risiko, Proaktif, Otonomi dan Agresivitas Bersaing sebagai 
variabel X. Maka dapat dikemukakan kerangka pemikiran sebagai berikut.

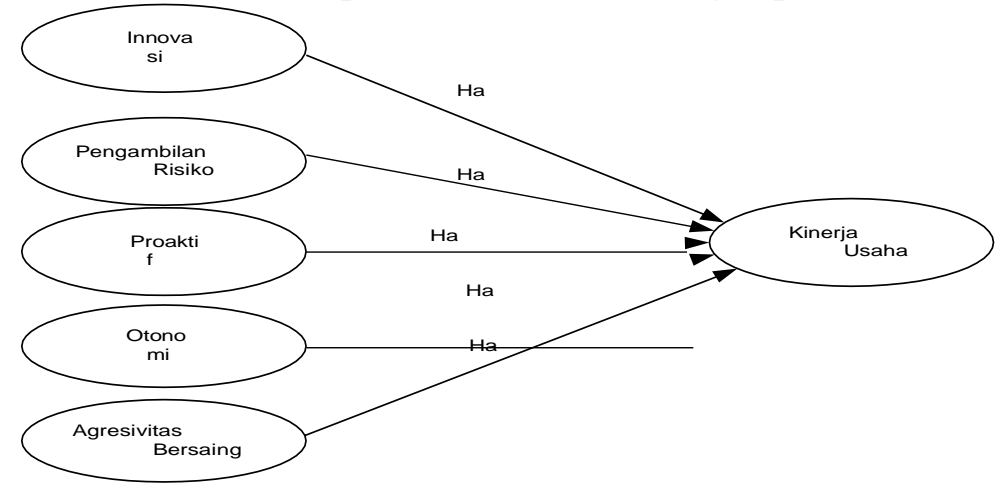

Gambar 2.1 Kerangka Pemikiran

Hipotesis dari model kerangka pemikiran di atas adalah sebagai berikut

Ha1: Terdapat pengaruh signifikan innovasi terhadap kinerja usaha Kerajinan Rotan di Kabupaten Cirebon

Ha2: Terdapat pengaruh signifikan pengambilan risiko terhadap kinerja usaha Kerajinan Rotan di Kabupaten Cirebon

Ha3: Terdapat pengaruh signifikan proaktif terhadap kinerja usaha Kerajinan Rotan di Kabupaten Cirebon

Ha4: Terdapat pengaruh signifikan Otonomi terhadap kinerja usaha Kerajinan Rotan di Kabupaten Cirebon

Ha5: Terdapat pengaruh signifikan Agresivitas bersaing terhadap kinerja usaha Kerajinan Rotan di Kabupaten Cirebon

\section{METODOLOGI}

Populasi adalah wilayah generalisasi yang terdiri dari objek atau subjek yang mempunyai kuantitas dan karakteristik tertentu yang ditetapkan oleh peneliti untuk dipelajari dan kemudian ditarik kesimpulan (Sugiyono, 2013:80).

Menurut Sugiyono (2013:84)) sampel adalah sebagian dari populasi. Sampel terdiri atas sejumlah anggota yang dipilih dari populasi.

Metode pengumpulan data yang digunakan adalah metode kuesioner tertutup. Data yang diperoleh adalah data primer. Data primer adalah data yang diperoleh langsung dari responden berupa jawaban pertanyaan dalam kuesioner (Supranto, 2011: 239). Dalam penelitian ini data yang digunakan adalah data dari hasil penyebaran kuesioner agar karakteristik responden yang sesuai dengan permasalahan.

\section{HASIL UJI STATISTIK}

Pengujian validitas data dalam penelitian ini diukur dengan menggunakan nilai convergent validity, average variance extracted (AVE) dan discriminant validity. Nilai convergent validity atau loading factor harus dapat lebih besar dari 0,7 dan jika nilai loading faktor dibawah dari 0,7 maka indikator tersebut dapat dihapuskan. Nilai average variance extracted (AVE) harus dapat lebih besar dari 0,5 dan nilai loading faktor diatas 0,7. Nilai average variance extracted (AVE) juga dapat digunakan untuk dapat menghitung nilai discriminant validity. Berikut ini merupakan hasil dari convergent validity, average variance extracted (AVE), dan discriminant validity. 
Setelah data-data telah melewati uji outer model pengolahan data variabel-variabel penelitian dapat dilanjutkan pada tahapan pengujian model struktural untuk dapat memenuhi kontribusi dari variabelvariabel independen $(\mathrm{X})$ terhadap variabel-variabel dependen $(\mathrm{Y})$. Berikut ini adalah kriteria pengujian model struktural yang harus dipenuhi dalam penelitian ini yaitu nilai dari, Goodness of Fit (GoF), path coefficientsdan koefisien determinasi $\left(\mathrm{R}^{2}\right)$,

\section{Hasil Pengujian Goodness of Fit(GoF)}

Untuk dapat melakukan pengujian kecocokan model dalam penelitian ini, nilai GoF (Goodness of Fit) dapat dihitung dengan cara manual dengan memasukan nilai AVE dan nilai koefisien determinasi.

Berdasarkan hasil dari perhitungan Goodness of Fit $(\mathrm{GoF})$ di atas, maka dapat disimpulkan bahwa model yang dapat digunakan dalam penelitian ini kecocokan model penelitian yang tergolong besar. Nilai GoF 0,1 tergolong kecil, nilai GoF 0,25 tergolong sedang dan nilai GoF lebih dari 0,38 tergolong besar.

\section{Path Coefficients}

Evaluasi path coefficient digunakan untuk menunjukkan seberapa kuat efek atau pengaruh variabel independen kepada variabel dependen. Sedangkan coefficient determination (R-Square) digunakan untuk mengukur, seberapa banyak variabel endogen dipengaruhi oleh variabel lainnya. Hasil $R$-Square sebesar 0,67 ke atas untuk variabel laten endogen dalam model struktural, mengindikasikan pengaruh variabel eksogen (yang mempengaruhi) terhadap variabel endogen (yang dipengaruhi) termasuk dalam kategori baik. Sedangkan jika hasilnya sebesar 0,33 - 0,67 maka termasuk dalam kategori sedang, dan jika hasilnya sebesar 0,19 - 0,33 maka termasuk dalam kategori lemah (Sarwono dan Budiono, 2012).

\section{DISKUSI}

Hipotesis yang pertama menunjukkan bahwa variabel inovasi terbukti berpengaruh secara signifikan terhadap kinerja usaha karena hasil dari nilai t-statistik inovasi sebesar 2,499 yang berarti lebih besar dari 1,96 dan p-values sebesar 0,013 yang berarti lebih kecil dari 0,05, Sehingga dapat disimpulkan bahwa inovasi memiliki pengaruh yang signifikan terhadap kinerja usaha. Hasil ini sesuai dengan penelitian Arshad, et al (2014) serta penelitian Larsen dan Korneliussen (2012) yang menyimpulkan bahwa inovasi berpengaruh terhadap kinerja usaha. Inovasi adalah salah satu instrumen dasar pertumbuhan strategies untuk masuk pasar baru, meningkatkan pangsa pasar yang ada dan untuk menyediaan perusahaan dengan keunggulan. Inovasi memberikan perusahaan sebuah orientasi strategis untuk mengatasi masalah yang dihadapi perusahaan oleh karena itu semakin baik inovasi maka semakin tinggi tingkat kesuksesan bisnis

Kemudian untuk hipotesis kedua menunjukkan bahwa variabel pengambilan risiko memiliki nilai t-statistik sebesar 2,450 yang berarti lebih besar dari 1,96 dan p-values sebesar 0,015 yang berarti lebih kecil dari 0,05, sehingga dapat disimpulkan bahwa pengambilan risiko memiliki pengaruh yang signifikan terhadap kinerja usaha. Hasil ini sesuai dengan penelitian Hatta (2014), Arshad, et al (2014) serta penelitian Hapsari dan Setiawan (2019) yang menyimpulkan bahwa pengambilan risiko berpengaruh signifikan terhadap kinerja usaha.

Untuk hipotesis ketiga menunjukkan bahwa variabel proaktif memiliki nilai t-statistik sebesar 2,202 yang berarti lebih besar dari 1,96 dan p-values sebesar 0,028 yang berarti lebih kecil dari 0,05, sehingga dapat disimpulkan bahwa proaktif memiliki pengaruh yang signifikan terhadap kinerja usaha. Hasil ini sesuai dengan penelitian Hapsari dan Setiawan (2019) dan

Arshad, et al (2014) yang menyatakan bahwa proaktif berpengaruh terhadap kinerja usaha. 
Perilaku proaktif sebagai upaya mengambil inisiatif dalam meningkatkan ide dan kreativitaskreativitas baru mengubah status quo dibanding hanya bertindak pasif dalam menghadapi kondisi saat ini.

Hipotesis keempat menunjukkan bahwa variabel otonomi memiliki nilai t-statistik sebesar 3,244 yang berarti lebih besar dari 1,96 dan p-values sebesar 0,001 yang berarti lebih kecil dari 0,05 . Sehingga dapat disimpulkan bahwa otonomi memiliki pengaruh yang signifikan terhadap kinerja usaha. Hasil ini sesuai dengan penelitian Gautam (2016 dan Hatta (2014) menyatakan bahwa otonomi berpengaruh positif terhadap kinerja usaha.

Hipotesis kelima menunjukkan bahwa variabel agresivitas bersaing memiliki nilai t-statistik sebesar 4,399 yang berarti lebih besar dari 1,96 dan p-values sebesar 0,000 yang berarti lebih kecil dari 0,05, sehingga dapat disimpulkan bahwa agresivitas bersaing memiliki pengaruh yang signifikan terhadap kinerja usaha. Hasil ini sesuai dengan penelitian Arshad (2014) dan Gautam (2016) menyatakan bahwa agresivitas bersaing berpengaruh terhadap kinerja usaha.

\section{KESIMPULAN}

Berdasarkan analisis dan pembahasan terhadap penelitian ini yang berjudul maka dapat ditarik kesimpulan sebagai berikut:

1. Inovasi berpengaruh signifikan terhadap kinerja usaha kerajinan rotan di Kabupaten Cirebon. Inovasi adalah sangat penting dalam lingkungan kompetitif untuk mendapatkan keunggulan kompetitif yang lebih tinggi dengan membuat inovasi produk baru maka akan meningkatkan kinerja usaha.

2. Pengambilan risiko berpengaruh signifikan terhadap kinerja usaha kerajinan rotan di Kabupaten Cirebon. Seorang wirausaha harus berani menghadapi risiko. Semakin besar risiko yang dihadapinya, semakin besar pula kesempatan untuk meraih keuntungan. Wirausaha yang sukses dinilai dari keinginannya untuk mulai bermimpi dan berani menanggung risiko dalam upaya mewujudkannya.

3. Proaktif berpengaruh signifikan terhadap kinerja usaha kerajinan rotan di Kabupaten Cirebon. Seorang wirausaha yang menjalankan usaha, harus bersikap proaktif jika usaha yang dijalankannya ingin berkembang terus-menerus

4. Otonomi berpengaruh signifikan terhadap kinerja usaha kerajinan rotan di Kabupaten Cirebon. Otonomi adalah keleluasaan atau kebebasan individu dalam berfikir dan bertindak kreatif dalam mengatasi berbagai persoalan atau dalam meng-optimalkan peluang baru yang menarik di pasar. Wirausaha adalah seseorang yang bebas dan memiliki kemampuan untuk hidup mandiri dalam menjalankan kegiatan usahanya atau bisnisnya atau hidupnya. Ia bebas merancang, menentukan mengelola, mengendalikan semua usahanya.

5. Agresivitas bersaing berpengaruh signifikan terhadap kinerja usaha kerajinan rotan di Kabupaten Cirebon. Sikap agresivitas bersaing yang kuat memungkinkan perusahaan untuk menjadi pemain yang menentukan dalam

\section{DAFTAR BACAAN}

Hair, J. F., Ringle, C. M., and Sarstedt, M. (2011). PLS-SEM:Indeed a Silver Bullet. Journal of Marketing theory and Practice, 19(2), 139-152.

Hapsari, Nurmalita Rhizky dan Setiawan, Achma Hendra (2019) Analisis Orientasi Kewirausahaan Terhadap Kinerja Usaha Industri Kreatif Bidang Kerajinan Di Kota Semarang. Diponegoro Journal Of Economics. Vol 1, No 1, hal. 47-54. 
Haryo Santoso dan Yengky Imam Susanto (2014) Faktor-Faktor Yang Berpengaruh Terhadap Kewirausahaan Di Klaster Industri Mebel Kabupaten Blora. Journal of Industrial Engineering Management. Volume : Vol 9, No.1: 1-10

Hatta, Iha Haryani (2014) Analisis Pengaruh Inovasi, Pengambilan Resiko, Otonomi, Dan Reaksi Proaktif Terhadap Kapabilitas Pemasaran Ukm Kuliner Daerah Di Jabodetabek. Jurnal Manajemen Pemasaran. Vol. 8, No. 2, Hal. 90-96

Hendro. (2011). Dasar-dasar Kewirausahaan. Jakarta: Erlangga.

Henseler, J., Ringle, C., dan Sinkovics. (2009). The Use of Partial Least Squares Path Modeling in International Marketing. Advances in International Marketing. Vol. 4 No.20 :277-319

Ida. (2015). Pengaruh Locus of Control, Financial Knowledge, Income terhadap Financial Management Behavior. Jurnal Bisnis dan Akuntansi Vol. 12 (3), 131-144.

Karimi, Saeid; Biemans, Harm J.A.; Lans, Thomas; Mulder, Martin; \& Chizari, Mohammad. (2011) Application of Structural Equation Modelling to Assess the effect of Entrepreneurial Characteristics on Students' Entrepreneurial Intentions. SSRN Electronic Journal. Vol. 5 (3) Hal. $1-15$

Knight, G. (2000). Entrepreneurship and Marketing Strategy: the SME Under Globalization. Journal of International Marketing. Vol.8, No.2 Hal. 1-19.

Kobia, M. \& Sikalich,D. 2010. Toward a search for the meaning of entrepreneurship. Journal of European Industrial Training, Vol 34(2): 110-127

Kotler, Philip dan Kevin Lane Keller. (2009). Manajemen Pemasaran. Edisi 13 Jilid satu. Jakarta: Erlangga

Kreiser P; (2015). Correlates of Entrepreneurship: The Impact of National Culture on Risk-taking Proactiveness in SMEs. Academy of Management Journal, 51(1), 97-111.

Kusumo, Agung Raharjo Wibowo. (2006). Analisis Faktor-faktor yang Mempengaruhi Inovasi Produk untuk Meningkatkan Keunggulan Bersaing dan Kinerja Pemasaran (Studi Industri Batik Skala Besar dan Sedang di Kota dan Kabupaten Pekalongan). Tesis. Universitas Dipenogoro, Semarang

Larsen, Nils Magne and Korneliussen, Tor (2012) Effects of entrepreneurial orientation on online retail performance Int. J. Electronic Marketing and Retailing. Vol. 5, No. 1: 77-93

Lebans, M., and Euske, K. (2006). A conceptual and operational delineation of performance. Cambridge University Press

Lee, S. M., and Peterson., S. J. (2000). Culture, Entrepreneurial Orientation, and Global Competitiveness, Journal of World Business. 3 (5): 1-14

Lee, S.M. and Peterson, S. (2000). Culture entrepreneurial orientation, and global competitiveness.

Journal of World Business. Vol 35, No. 4: 401-416

Lumpkin, G. T., \& Dess, G. G. (1996). Clarifying the entrepreneurial orientation construct and linking it to performance. Academy of Management Review, 21(1), 135-172.

Lupiyoadi, Rambat. (2013). Entrepreneurship (From Mindset to Strategy). Jakarta: Lembaga Penerbit Fakultas Ekonomi Universitas Indonesia.

Madhoushi, Mehrdad et al. (2011), Entrepreneurial Orientation and Innovation Performance: The 
Mediating Role of Knowledge Management. Asian Journal of Business Management 3, vol. 4. pp. 310-316

Malhotra, Naresh K. (2012). Riset Pemasaran Pendekatan Terapan. Jakarta: Index.

Noor, Henry Faizal (2007) Ekonomi Manajerial, Jakarta : Raja Grafindo Persada,

Okpara, J. O. (2009). Strategic Choices, Export Orientation And Export Performance of SMEs in Nigeria. Management Decision. 5 (47):1281-1299.

Primiana, Ina. (2009), Menggerakkan Sektor Riil UKM \& Industri. Bandung: Penerbit Alfabeta Primiana, Ina. (2009), Menggerakkan Sektor Riil UKM \& Industri, Penerbit Alfabeta, Bandung

Ranto, Dwi Wahyu Pril. (2016). Membangun Perilaku Entrepreneur Pada Mahasiswa Melalui Entrepreneurship Education. Jurnal Ilmu Pendidikan, Vol 17 No.2: 121-129

Runyan, R. C., Ge, B., Dong, B., \& Swinney, J. L. (2012). Entrepreneurial orientation in cross cultural research: Assessing measurement invariance in the construct. Entrepreneurship Theory and Practice. 36(4): 819-836.

Sampurno (2010). Manajemen Strategik: Menciptakan Keunggulan Bersaing yang Berkelanjutan. Yogyakarta: Gajah Mada University Press

Sarwono, Jonathan dan Budiono, Herlina. (2012). Statistik Terapan: Aplikasi (Untuk Riset skripsi, Tesis dan Disertasi Menggunakan SPSS, AMOS, dan Excel). Jakarta: Elex Media Komputindo. 